\title{
A regional cuisine database to support the revitalization of a local area in Japan
}

\author{
T. Oyabu \\ Kanazawa Seiryo University, Japan
}

\begin{abstract}
There are nine private houses in the village of Otsuchi-machi, which is located in the Ishikawa prefecture of Japan. However, only three people are living in two houses now. The district is an intermediate and mountainous area. It is now in a state of decay and half-deserted, but it used to have a lot of life in the old days, due to agriculture and forestry. In this study, an increase in the number of visitors is investigated based on various kinds of resources, for example the natural beauty of the area and local dishes (including unique mountain vegetables). There is a possibility that village people could live sustainably by offering a combination of local dishes and the experience of charcoal burning. It was deemed to be necessary to construct a database of mountain-vegetable dishes to meet a wide variety of visitors' demands. Visitors can make a reservation through the same database, which is user-customized. It is more important to revitalize a local area in Japan than to contribute to improving the facilities at famous tourist spots.
\end{abstract}

Keywords: local revitalization, rural-tourism measure, mountain vegetable.

\section{Introduction}

It has been told that the inhabitants in Otsuchi-machi used to be Heike warriors that escaped from Genji, who vanquished the Heike. The village is located in Kaga city, in the Ishikawa prefecture of Japan. One hundred and forty one people (21 houses) were living there in 1916. The number of people had decreased to 21 residents by 1982. There was a branch of an elementary school and there were lots of activities until around 1965 in the area [1]. There was a massive fire in 1938 and thatched houses were burned out. There are now nine houses and three people living in two houses. They are one couple and a woman. Seven old 
houses are vacant. Those houses are now disappearing. Mountainous villages, which have good old Japanese history, are disappearing as well as the other country areas. Some former inhabitants have a house in neighboring towns and visit the village to work on a farm on Saturday and Sunday. It costs about 1,300 (US\$/person) to live in the area. It is necessary to increase the number of visitors who can consume in the area in order to maintain the living system and the environment [2].

The study on Otsuchi area started in 2007. The area has many kinds of resources for visitors, for example a charcoal kiln, mountain vegetables, rare nuts and nature. The region has many charms for inhabitants living in Kanazawa city, which has a population of 460,000 and is also a recreation and healing area. Visitors can benefit from getting rid of stress and accumulated fatigue. Many workers have the stress and fatigue due to the IT society and heavy labor environment. A measure to develop reasonable visitor numbers is proposed in this study. The measure is constructed particularly about the vegetable dishes from in and around the mountains, and local dishes gathered in Otsuchi [3]. The dishes are also environmentally friendly. As a result, target visitors are guests for a day and middle-aged females. Small groups of office ladies are also target guests. A group of about five people is reasonable in the area [4]. The refreshment effect on visitors can be expected from the local dishes, charcoal burning and experience of foraging for edible wild mountain plants.

The labor load of inhabitants is lightened by accepting only small-group guests for a day and an environmentally-friendly exchanging strategy can be maintained. There is Kikuno-yu, which is a community spring bathhouse, and many kinds of spring inns near Otsuchi-machi. These facilities are introduced when there are people who hope to get into a hot spring or stay at an inn. The toilet has to be promoted when many guests visit the area. The eco-toilet has already been developed and installed at Mt. Fuji. It is able to promote environmentally-friendly guests [5]. Development of the IT environment is necessary for young people to visit, namely every person can connect to the Internet in the area. The results of the study on the information system and services for guests are described in this investigation.

\section{Local dishes}

Agricultural products and charcoal had been the inhabitants' bread and butter until around 1960 in the Otsuchi area. Some kinds of vegetables were produced by burn agriculture, which can sterilize soil. The ashes become fertilizer. Burn agriculture shifts to other places within a period of around five years. For example, buckwheat and vegetables are grown in the first year and foxtail millet in the second year. Red beans are planted in the third year and Japanese millet in the fourth and fifth years. Foxtail millet and Japanese millet are the staples of Otsuchi in place of rice. A photograph of Otsuchi is shown in Fig.1. Sushi rolled with persimmon leaves and dishes using brake, ostrich fern and wild melon (not sweet) as ingredients are famous local dishes. The foods are good for our health and effective in curing various kinds of adult diseases. The dishes are attracting 


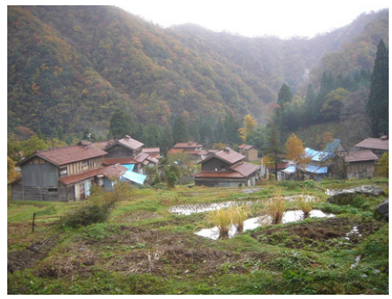

Figure 1: $\quad$ Photograph of the Otsuchi area.

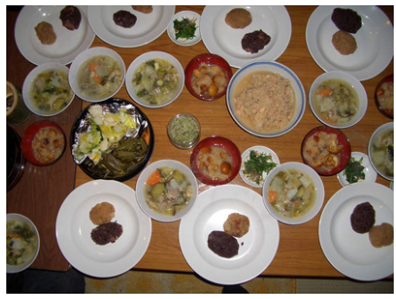

Figure 2: $\quad$ Some local dishes.

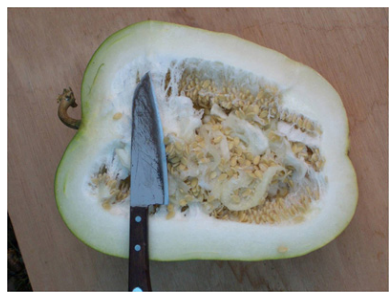

Figure 3: Wild melon.

by some visitors. It is necessary to develop the dishes to make them suitable for visitor's tastes. The dishes vary seasonally. Seasonal foods should be provided as much as possible. It is necessary to enhance the guest's satisfaction using seasonal and effective ingredients for modem-day illnesses (high-blood pressure, diabetes and hay fever) and adult-onset diseases (stroke, cancer and heart disease). In the study, the standard and guest-customized dishes can be provided via the internet to meet customer's needs. The ingredients used should be carefully selected. Since metabolic syndrome has become a serious issue in Japan, the host (PC server) makes healthy choices about the dishes based on the guest's condition. A meeting with the local public is also effective. It was held last year and 50 visitors (including elementary school students) attended the meeting with foods. They found the meeting to be satisfactory. Some of the dishes are shown in Fig.2. The following evaluations were received by participants, namely good fun dinner, old feeling and dishes (especially wild melon dish) and good dishes prepared over a hearth fire. The picture of wild melon is shown in Fig.3. Residents in a neighboring town are interesting in the area and the dishes but there are some issues, namely access matters, time and communications problems. Reasonable visitor numbers are required in the area at any time.

\section{Target visitor}

Young women are expected to be the principal visitors in the area because they can afford to visit and, relatively, have time to do so. They are considered as the main target. However, they are sensitive to dishes and focus more on high- 
quality ones than men. It is necessary to combine farming experiences (green tourism), charcoal burning and the local dishes of the Otsuchi area in order to satisfy those young women. One-day visiting is a basic. Visitors can spend the day lazing in the area, reading a book and talking with local residents. The area can provide a cup of coffee or tea with sweets (bean cake, etc.) as a snack at 10:00 and 15:00. There is delicious and safe flowing water shown in Fig.4. Green horseradish paste (wasabi) grows around the water. The area has terraced rice fields and the scenery of the mountain village nurses our soul. No visitors are attracted by doing nothing. It is to have some sort of idea of how to maintain the number of visitors. Approaches to the following organizations or groups in neighboring cities are effective, and as a result of the study have been contacted, for example by PR and circulars:

Women's Clubs, agricultural cooperatives, labor unions

Recently, company recreation facilities in hot spring areas have been closing because it is difficult to meet the cost of maintenance. Many guests choose a one-day trip over a trip staying overnight as they are very busy. They prefer the low-cost trip and the location, which is not far from their home. The area can take a major role as a public health facility of a company. The visitors can take a hot spring (Kikuno-yu) at a cheaper price by couponing. One measure is to be interviewed by a LOHAS (lifestyles of health and sustainability) magazine; this is necessary and attaching coupons to the magazine is effective. The facilitycapacity for guests has to be filled. As a first step one house begins the service and all the three houses can operate the facilities after the business is going smoothly. They can work together and incorporate the business. The goal of the residents is to earn over 1,300 US\$ per month (per person).

\section{Experience tour}

\subsection{Experience tour of charcoal burning}

Some visitors hope to have an experience (for example a farming experience), but also hope to enjoy local dishes of the mountain area. The guest can renew oneself in body and spirit by having the experience, which differs from routine

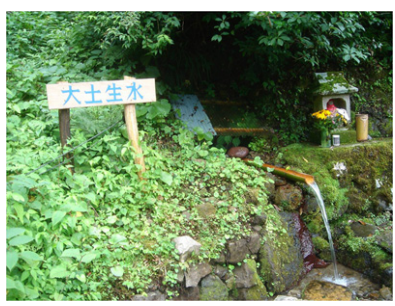

Figure 4: $\quad$ Photograph of the flowing water in Otsuchi. 
work, and gaining knowledge. There are the following experiences for visitors in the Otsuchi area:

rice planting, working on a farm, charcoal burning;

hiking, foraging for edible wild mountain plants

These experiences are interesting, especially to mature women in Japan. It takes some time to finish charcoal burning, so burned charcoal is couriered to the guest's house afterwards. The guest desires added values from the charcoal that they have manufactured. One of the values is the air purification function. The burning materials are mainly cider, cypress, bamboo and oak. Origami, which is contained in a steel box, is sometimes burned with the wood materials and is marketed. A photograph of the charcoal kiln is shown in Fig.5. The charcoal has various kinds of functions and some people use the functions (capabilities). One of the functions is an adsorption capability for air contaminated chemicals. Recently, indoor air quality has declined due to building materials, including VOCs (volatile organic compounds). Charcoal is effective at removing the chemicals. Other experiences can also be conducted by communicating with the inhabitants. It is difficult for amateurs to forage for edible wild mountain plants. The name and safety of the plant should be confirmed, as some kinds of fungus or mushrooms are poisonous. Rice planting can be performed in slightly terraced rice fields. The visitors can attend the experience without difficulty by being prepared with work clothes and tools. It is better to sell the originally grown ingredients (organic foods) through a website. The first priority is that the inhabitants can earn money to live there.

\subsection{Purification capability of manufactured charcoal}

Charcoal has the function of purifying air contaminants. This is an important additional value. The guest becomes more interested in the charcoal burning due to understanding its value. The adsorption capability for formaldehyde, which is a causative chemical in sick building syndrome, is examined in this study. The guideline is $0.08 \mathrm{ppm}$ in an indoor environment. The photograph of the examined charcoal is shown in Fig.6. The subjective charcoal is Japanese cider (about 0.85 $\mathrm{kg}$ ). It is installed in an experimental sealed chamber made of acrylic and the volume is about 300 liters. Formaldehyde is injected until the concentration of

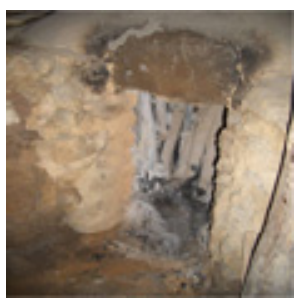

Figure 5: Entrance to the charcoal kiln. Figure 6: The height is about $160 \mathrm{~cm}$.

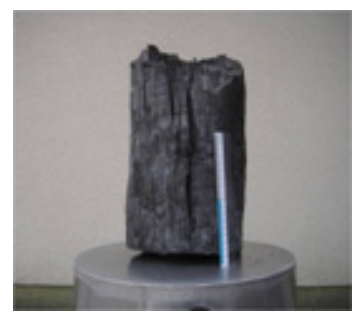

Examined cider charcoal. 


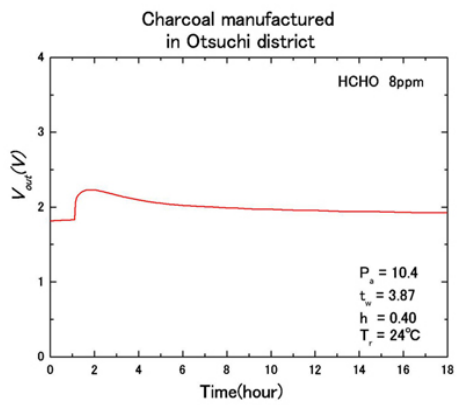

Figure 7: Adsorption characteristic of cider charcoal to formaldehyde of 8 ppm.

$8 \mathrm{ppm}$ is obtained using a micro syringe. The concentration is 100 -fold to the guideline. The adsorption characteristic is measured using a tin oxide gas sensor, which can output the concentration as a dc voltage. The result is indicated in Fig.7. The baseline is measured for one hour and the chemical is injected into the chamber. The sensor characteristic increases rapidly at the same time. It decreases due to the adsorption effect of the charcoal. The evaluation index $\left(P_{a}\right)$ is proposed and the equation is represented using equation (1). The output height from the baseline is named as $h$ and the half-value width is named as $t_{w}$. The $h$ becomes larger as the concentration becomes higher. The $t_{w}$ becomes shorter when the capability is higher. As for the result, $P_{a}=10.4$ is derived and the value is the same as a potted cyclamen. There are many kinds of trees in the Otsuchi area. It is necessary to find a charcoal material that has a higher purification capability.

$$
P_{a}=h / t_{w} \times 100(\%)
$$

\section{Local products}

There is a variety of local foods in Otsuchi. They are agricultural products, wild vegetables and rare nuts. Delicious rice can be produced in the terraced paddy fields of the mountain area, which is sold at a high price. There is spring water near the rice terraces. Wasabi (green horseradish), trefoil and parsley are growing there. The plants have a benefit on our health. There had been a sericultural industry in the area until 1935 and mulberry trees were planted, but did not make much money. The industry shifted from sericulture to charcoal production in the domain-duties period as the charcoal price rose sharply. The charcoal industry continued until about 1955 . There are effective local products, mainly charcoal products, which are carbon-neutral, and local dishes, which are effective on our health. The several kinds of nut harvested by visitors are indicated in Fig.8. 


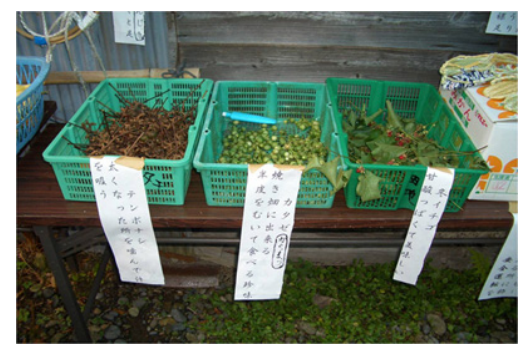

Figure 8: $\quad$ Photograph of the harvested nuts.

\section{Utilization of old form house}

\subsection{Database system for local dishes}

The sustainable measure for increasing visitors is described in the previous sections. The concrete proposals, which are based on an IT system, are given in this section [6]. Old style houses have rapidly disappeared in Japan. Those houses should be preserved forever and utilized. There are nine old houses in the Otsuchi area. A database for wild mountain plant dishes should be constructed and an information system communicated using the Internet also established. Ordinary people can access a website and obtain information through the system (for example a website). The schematic diagram is illustrated in Fig.9. Various kinds of tourism resources (they are called tourism parts) are memorized in the database, which is a server. The experience and local dishes are the main tourism parts. Guests can access the web service through an information terminal and combine the parts according to their taste, which are memorized in the database. The visiting places and dishes can be customized to individual preference. Seasonal dishes are also prepared. A diagram of the services is summarized in Fig.10. The main service of the system is to customize the country dishes and for reservations. Users and tour agents of the tour can enter the requested items. Users of the service can make a reservation for food after communication with the system. In the process, a user can combine parts of local dishes, which are recorded in the database, and state a preference for suitable dishes. In the combining process, fuzzy logic and genetic algorism are adopted for recording decisions of guest-taste.

The database consists of the cooking, ingredient and disease tables. There are two association tables, namely dish and effectiveness. The dish table associates the cooking table with the ingredient table. The effectiveness table associates the ingredient table with the disease table [7]. The entity relation is represented in Fig.11. The cooking table has the following items, dish name, calorie, recipe and photograph. The ingredient table has following items, ingredient name and season. 


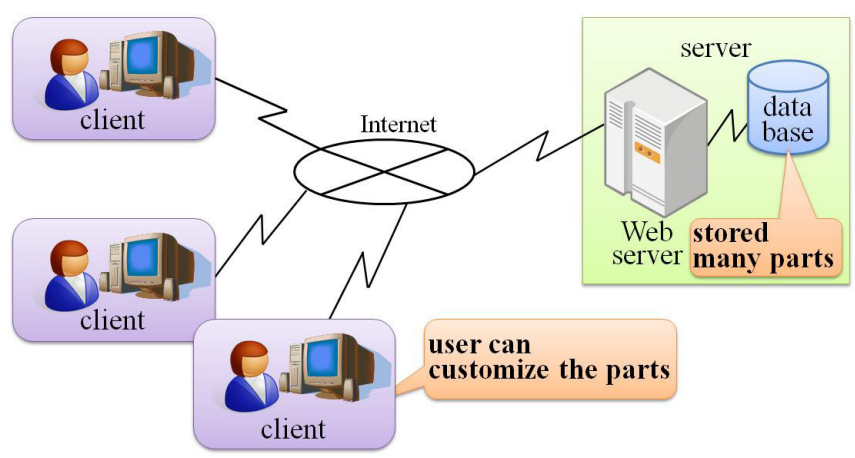

Figure 9: Schematic diagram of the constructed system.

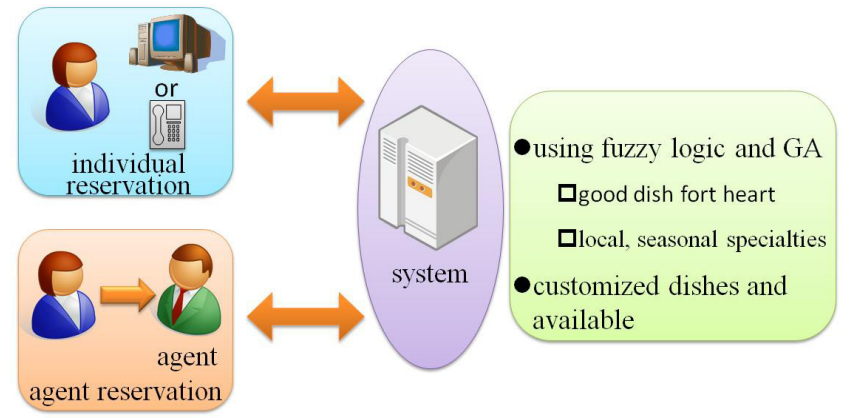

Figure 10: Service process.

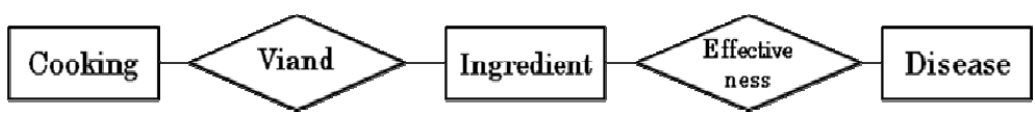

Figure 11: Entity relation table.

\subsection{Cooperation experiences and dishes}

The guests visit Otsuchi not only to experience the local dishes, but also to enjoy various kinds of resources. It is thought that the cooperation of the charcoal experience and local dishes is effective. Recently, many people have become stressed out from work and seek healing and a chance to think things through in a relaxed and comfortable environment. Visitors can be maintained by constructing the area achieved from LOHAS (lifestyles of health and sustainability) and slow life. Slow life aims to achieve local production for local consumption. LOHAS means to aim to improve one's health and achieve a sustainable society. The Otsuchi area should be established as an experiencing area for various kinds of tourism resources without the destruction of nature and it should maintain a senior-friendly community. The relationship among the tourism resources is illustrated in Fig.12. 


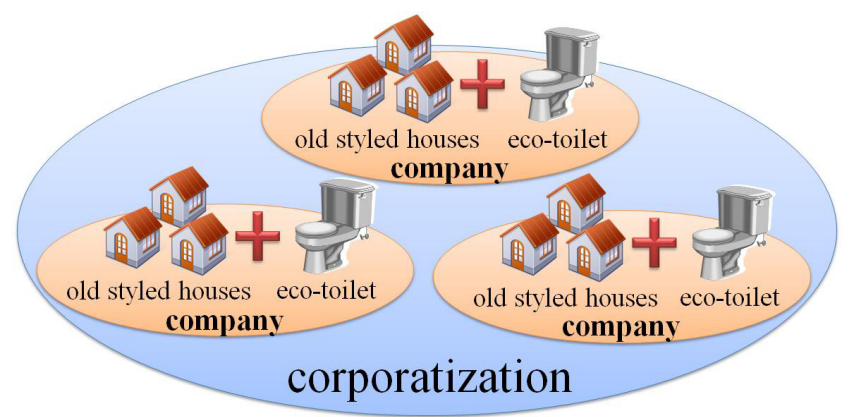

Figure 12: Collaboration with the experiences and local dishes.

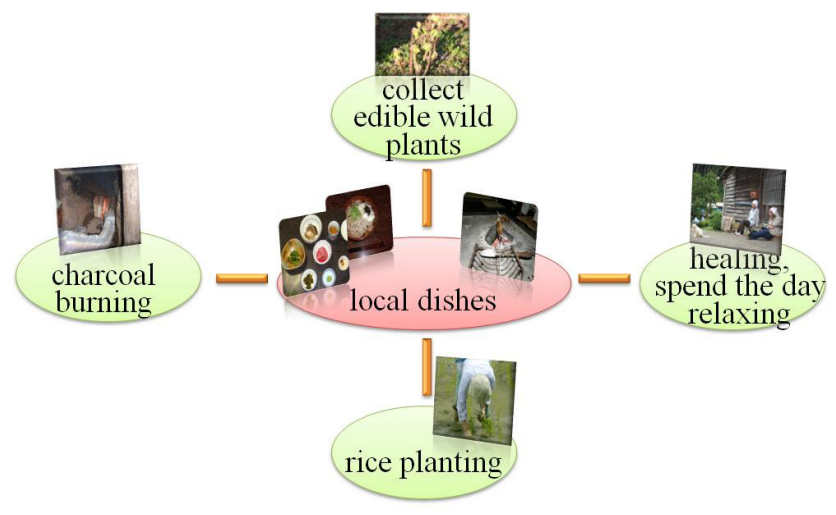

Figure 13: Group formation of the old styled houses. The toilet, which is environmentally conscious, is absolutely necessary.

\subsection{Corporatization}

It is a precondition for the inhabitants to have a hospitality-oriented and environmental spirit. It is also natural that they have management identification for maintaining visitors. Guests could not visit a bad environmental region. It is necessary to construct a system that can be concerned about individual health. It is desirable to divide the nine old styled houses into three groups and manage every group. In the meantime, one house begins the tour business and a group starts the business as a company. The sense of duty and the spirit maintaining the area are fostered by the corporatization. The image of corporatization is represented in Fig.13. Each company competes and works together with each other when needed. The wisdom and innovative ideas of the company president are important.

The local dishes and experiences in the Otsuchi area need to be permeated deeply among the populace. Therefore, interviews for a LOHAS magazine are 
effective in inviting visitors. Some presents and coupon tickets in order to receive the discount are attached to the magazine. The target is small groups of women. They have plenty of money to spend on themselves in Japan. The company ties up with the Women's Clubs in Kanazawa and Kaga City, Japan Agricultural Cooperatives and labor unions. It is very effective to tie up with a combination of companies as public welfare work to heal job stress. It is difficult for a company to maintain a resort facility owned by the company. The Japanese worker is under time constraints and is difficult to stay at a logging facility. A one-day trip is popular for refreshing one's body and sensorium. It has a large merit for cost and time. The relationship among small groups of women, inhabitants and the labor union is indicated centered around the magazine in Fig. 14.

\section{Conclusion}

A measure for revitalizing the Otsuchi area is proposed. The measure is to collaborate with the local dishes and charcoal burning experience. Low cost, a short distance away and short duration are the requirements for a refreshment trip due to the social circumstances in Japan. The Otsuchi area meets these requirements. The area has lots of relaxing spaces for one-day visiting, but the inhabitants have a low income to some degree. Foods are life giving. A database of food-ingredients produced locally is constructed and the guest can customize the ingredients and the experiences to individual preferences. In the database, three tables (cooking, ingredient and disease) are adopted and two association tables are also used. The system has been put to practical use since 2009. There are, however, some points for improvement. The number of visitors can be increased in the area by using a measured and sustainable system. There are needs that can potentially be met by the trend of public opinion. It is important to put the resources into commercial use and pay attention to the needs of visitors.

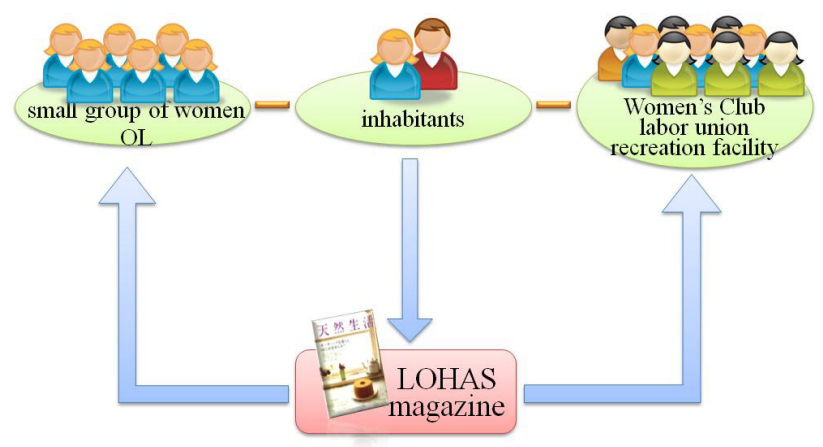

Figure 14: $\quad$ Promoting collaboration with a journal publisher. 


\section{References}

[1] Investigation Board on Higashitani district-preservation, Weather the hardships and give a light to mind, 2006. (in Japanese)

[2] Set, T., Things that can be done, where one can, operatively, Kanko, No.489, pp.26-27, 2007. (in Japanese)

[3] Yomiuri shinbun morning edition, enlightened kitchen and fish dish in an old styled house, 12 January 2007. (in Japanese)

[4] Yomiuri shinbun morning edition, mountain near village and widespread dream, 28 May 2007. (in Japanese)

[5] Yomiuri shinbun morning edition, mountain-friendly ecological toilet, 14 August 2007. (in Japanese)

[6] Pauline J. Sheldon, Tourism Information Technology, CABI Publishing, New York, USA (2003)

[7] C. J. Date, An Introduction to Database Systems, Addison Wesley, Boston, USA (2003) 